\title{
APPLICATION OF ADSORBENTS IN RADIONUCLIDE SEPARATION FOR RADIO-CHRONOMETRY PURPOSES
}

\author{
Mykola Strilchuk', Igor Maliuk', Ivan Mironyuk², Hanna Vasylyeva ${ }^{3}$, \\ Volodymyr Tryshyn', Maryna Hryhorenko', Oleksandr Zhukov', Khrystyna Savka²
}

${ }^{1}$ NAS of Ukraine Institute for Nuclear Research, Laboratory of Nuclear Forensics, Kyiv, Ukraine ${ }^{2}$ Department of Chemistry, Vasyl Stefanyk Precarpathian National University, Ivano-Frankivsk, Ukraine 3Department of Theoretical Physics, Uzhgorod National University, Uzhgorod, Ukraine

\begin{abstract}
The aim of this work is the application of well-known adsorbents for the separation of ${ }^{90} \mathrm{Sr}$, ${ }^{\circ} \mathrm{Y}$, and ${ }^{90} \mathrm{Zr}$ radionuclides. Three basic types of adsorbents have been studied: Dowex HCR S/S cation exchange resin, Dowex $1 x 8$ anion exchange resin, and titanium dioxide with a chemically modified surface. The most effective adsorbent for the separation of strontium, yttrium, and zirconium ions was titanium dioxide with a chemically modified surface. This adsorbent selectively absorbs zirconium cations against the background of excess strontium and yttrium ions. The separation takes place in $2 \% \mathrm{HNO}_{3}$ at initial concentrations of the studied cations $10 \mathrm{ng} / \mathrm{ml}$ and $10 \mathrm{O} \mathrm{ng} / \mathrm{ml}$. Analysis of the initial mixture and the mixture after separation was conducted using ICP-MS "Element-2" with argon plasma. Age of ${ }^{\circ 0} \mathrm{Sr}-{ }^{\circ} \mathrm{Y} \beta^{-}$-source (approximately 30.2 years old) was measured using the method of the chemical separation of ${ }^{90} \mathrm{Sr}$ and ${ }^{\circ} \mathrm{Zr}$ by the titanium dioxide and following calculation of the ${ }^{90} \mathrm{Zr} /{ }^{\circ} \mathrm{Sr}$ ratio. The age of ${ }^{\circ} \mathrm{Sr}-9 \mathrm{~S}^{\circ} \mathrm{Y} \beta^{-}-\mathrm{source}$ was calculated as $31.9 \pm 1$ year. The combination of liquid scintillation counting of $90 \mathrm{Sr}$ and ICP-MS analysis was proposed as an alternative method of determination of the ${ }^{90} \mathrm{Zr} /{ }^{\circ 0} \mathrm{Sr}$ ratio. It was shown, that both methods provide similar results

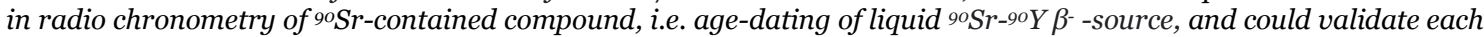
other.
\end{abstract}

Keywords: Strontium, yttrium, zirconium, separation, ICP-MS, liquid scintillation counting

\section{INTRODUCTION}

Accurate radionuclide separation is necessary for archaeological dating or in nuclear forensics to determine the age of unknown ${ }^{90} \mathrm{Sr}$-containing devices $[1,2]$. The isotopic ratio of ${ }^{90} \mathrm{Sr}\left(\beta^{-}\right)-{ }^{90} \mathrm{Y}\left(\beta^{-}\right)-{ }^{90} \mathrm{Zr}$ (stable), measured using ICP-MS, serves as a radio chronometer and can be used to determine the date of fabrication of a ${ }^{\circ} \mathrm{Sr}-{ }^{\circ} \mathrm{Y}$ radioactive source. The half-life of ${ }^{90} \mathrm{Y}$ is much shorter (64 hours) than that of ${ }^{90} \mathrm{Sr}$ ( 28,8 years). On elapse of time equal to several half-lives of yttrium, the amount of ${ }^{\circ} \mathrm{Y}$ becomes constant [3-6]. Therefore, the number of ${ }^{90} \mathrm{Sr}$ and its "granddaughter" ${ }^{90} \mathrm{Zr}$ nuclei, i. e., the ${ }^{90} \mathrm{Zr} /{ }^{90} \mathrm{Sr}$ ratio is an important parameter for nuclear forensics, thus methods of chemical separation of these elements become the main direction of scientific research in this field. The most effective method of separating the elements is the adsorption method $[3,4]$ at present time.

Liquid Scintillation Counting (LSC) offers unmatched convenience and sensitivity for pure betaemitters, such as ${ }^{\circ} \mathrm{Sr}$ or ${ }^{\circ} \mathrm{Y}$ [6-8]. While LSC has disadvantages as quenching, requiring cocktail, and little selectivity, it has an advantage as $4 \pi$ geometry and high efficiency. LSC detects radioactivity via the same type of light emission events that are used in the solid scintillator. The key difference is that the scintillation takes place in a solution of a scintillator. This allows close contact between the radioactive isotopes and the scintillator substance.

From another hand, inductively coupled plasma mass spectrometry (ICP-MS) is an analytical technique that can be used to measure elements at trace levels in a liquid's medium. From a laboratory perspective, the most significant advantage of ICP-MS is its multielement capability, which allows multiple elements to be measured simultaneously in a single analysis. The high sensitivity of ICP-MS provides the use of this analytical method in nuclear forensics.

Many different adsorbents are proposed for the adsorption of heavy metal cations and radionuclides, for example, zeolites [9], salts of polyvalent metals [10], mesoporous $\mathrm{TiO}_{2}$ [11-17]. Separation of $\mathrm{Sr}, \mathrm{Y}$, and $\mathrm{Zr}$ elements is often performed using ion exchange resin [18-22]. As usual, ion exchange resin is cross-linked polystyrene with different types of active groups, for example, sulfonic groups $-\mathrm{SO}_{2} \mathrm{OH}$ giving strongly acid cation exchangers [18]; carboxylic groups $-\mathrm{COOH}$ giving weakly acid cation exchangers [22]; quaternary ammonium groups $-\mathrm{NR}_{3}{ }^{+}$giving strongly basic cation exchangers [20] as well as chelators agent onto neutral polymeric matrix [21].

The aim of this work is the application of wellknown adsorbents for the separation of ${ }^{\circ} \mathrm{Sr},{ }^{\circ} \mathrm{Y}$, and ${ }^{\circ} \mathrm{Zr}$ radionuclides and calculate the age of ${ }^{\circ} \mathrm{Sr}-{ }^{\circ}{ }^{\circ} \mathrm{Y} \beta^{-}-$ source using the method of the chemical separation of 
${ }^{90} \mathrm{Sr}$ and ${ }^{\circ} \mathrm{Zr}$ by the best adsorbent in this field. The aim of this work is also to compare the obtained results with the combination of LSC of ${ }^{\circ} \mathrm{Sr}$ and ICP-MS analysis of peak with 90 amu as an alternative method of determination of the ${ }^{90} \mathrm{Zr} /{ }^{\circ 0} \mathrm{Sr}$ ratio.

\section{EXPERIMENTAL TECHNIQUES}

\subsection{Adsorbents}

Three basic types of adsorbents have been studied: Dowex HCR S/S cation exchange resin with active sulfonate groups, Dowex 1x8 anion exchange resin having quaternary amines in its structure [17], and mesoporous anatase modification titanium dioxide with a chemically modified surface. Dowex 1x8 and Dowex HCR S/S are commercially available adsorbents. Titanium dioxide of anatase modification was synthesized in the Chemical Department of V. Stefanyk Precarpatian National University (Ivano-Frankivs'k, Ukraine) [17].

Active adsorption sites of adsorbents are shown in Fig.1.

(a)<smiles>[R][N+]([R])([R])[N+]([R])([R])[NH3+]</smiles>

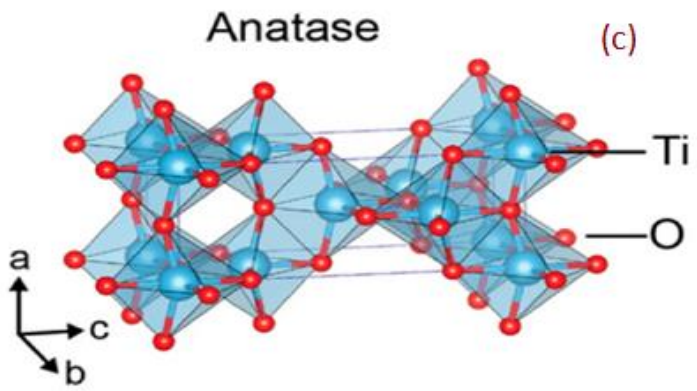

Figure 1. The sulfonic groups $-\mathrm{SO}_{2} \mathrm{OH}$ active site of Dowex HCR-S/S (a) and quaternary ammonium groups $-\mathrm{NR}_{3}{ }^{+}$ (Dowex 1x8) (b). Titanium dioxide of anatase modification (c). The structure of titanium dioxide was adapted from publication [11].

\subsection{Chemical separation of stable strontium, yttrium, and zirconium ions from their mixture}

The chemical separation of stable strontium, yttrium, and zirconium ions from their mixture was performed using stable isotopes ${ }^{88} \mathrm{Sr},{ }^{89} \mathrm{Y},{ }^{90} \mathrm{Zr}$. Separation of these elements by cation exchange resin and titanium dioxide was performed from a $2 \% \mathrm{HNO}_{3}$ medium with HF micro impurities. The separation of strontium and zirconium ions by Dowex 1x8 occurs in a $5 \% \mathrm{HCl}$ medium and for subsequent analysis using ICPMS a solution of $5 \% \mathrm{HCl}$ is evaporated for 5 hours, and then the dry residue is dissolved in $2 \% \mathrm{HNO}_{3}$ (Optima).

Several series of investigations were performed for the effective analysis of the chemical separation of the elements. In the first series of the studies, the initial mixture of stable isotopes with concentrations of 10 $\mathrm{ng} / \mathrm{ml}$ was used. The weight of the adsorbent was 100 $\mathrm{mg}$, the volume of the mixture was $10 \mathrm{ml}$. Duration of interaction $60 \mathrm{~min}$. The initial concentration of elements (stable isotopes) in the mixture was increased to $100 \mathrm{ng} / \mathrm{ml}$ in the second series of studies, other conditions of the experiment remained the same.

In the third series of studies, a mixture of $100 \mathrm{ng} / \mathrm{ml}$ of each element was used, however, the volume of the solution was $1 \mathrm{ml}+1 \mathrm{ml}$ of pure nitric acid. Accordingly, the mass of $\mathrm{TiO}_{2}$ decreased by 0.02 g. High-purity standards were used to prepare a mixture of strontium, yttrium, and zirconium. Analysis of the initial mixture and the mixture after separation was conducted using ICP-MS "Element-2" with argon plasma.

\subsection{Chemical separation of ${ }^{\circ} \mathrm{Sr}$ and ${ }^{90} \mathrm{Zr}$ in liquid ${ }^{90} \mathrm{Sr}-{ }^{90} \mathrm{Y} \beta^{-}$-source using titanium dioxide}

$1 \mathrm{ml}$ of ${ }^{90} \mathrm{Sr}$ liquid ${ }^{90} \mathrm{Sr}-{ }^{\circ} \mathrm{Y} \beta^{-}$-source, was diluted with $1 \mathrm{ml}$ of pure $2 \% \mathrm{HNO}_{3}$ (Optima) and $20 \mathrm{mg}$ of $\mathrm{TiO}_{2}$ was added to this solution. The separation process was performed for $120 \mathrm{~min}$ with weak stirring. Then the solution was filtrated and diluted 5 times. It was the "sample after separation". The initial solution of ${ }^{90} \mathrm{Sr}$ source was diluted 10 times, and was the "unseparated sample”. Samples were analyzed by ICP-MS.

\subsection{ICP-MS analysis}

The mixture of investigated elements was ionized in argon plasma and after transiting through the ion optics system, ions arrive at the mass analyzer. The signal measured by the ICP-MS detector is in units of counts per second CPS. External calibration was provided using calibration Standard A solution. The inductively coupled plasma mass spectrometry was performed using mass- spectrometer "Element-2". It has the following characteristics: dual-mode secondary electron multiplier (SEM); low dark noise: <0.2 Cps; sample times of down to $100 \mu \mathrm{s}$; large SEM plateau range $\sim 300$ $\mathrm{V}$; dynamic range $0.2 \mathrm{Cps}-5^{\cdot 10^{8}} \mathrm{Cps}$. Formation of polyatomic ions and tailing interference were controlled by measuring ${ }^{88} \mathrm{Sr}^{16} \mathrm{O},{ }^{89} \mathrm{Y}^{16} \mathrm{O}$, and ${ }^{90} \mathrm{Zr}^{16} \mathrm{O}$ amounts, as well as the formation of ${ }^{8}{ }^{9} \mathrm{Y}^{1} \mathrm{H}$. The efficiency of detecting investigated elements was measured twice: for initial concentration of the elements on the 10-ppb level, and initial concentrations of the elements on the 100-ppb level. The ICP-MS spectrum of the ${ }^{90} \mathrm{Sr}-{ }^{\circ} \mathrm{Y}$ radioactive source is shown in Fig.2.

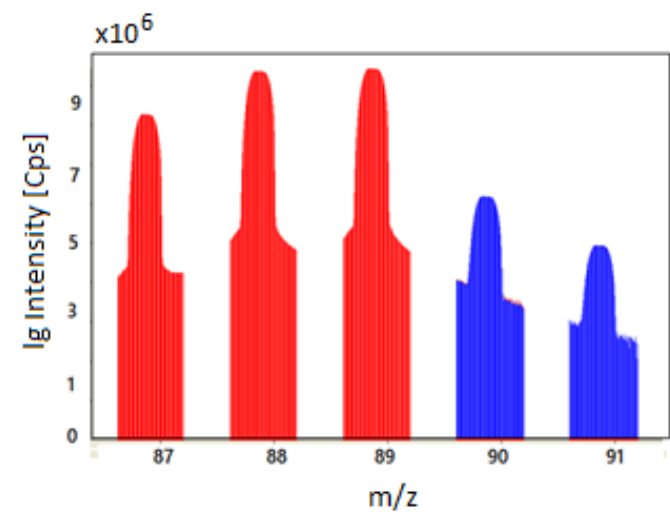

Figure 2. The ICP-MS spectrum of the ${ }^{90} \mathrm{Sr}-{ }^{\circ} \mathrm{Y}$ radioactive source. 


\subsection{Liquid scintillation counting of ${ }^{90} \mathrm{Sr}-9{ }^{\circ} \mathrm{Y}$ source}

The quantity of ${ }^{90} \mathrm{Sr}$ was controlled by liquid scintillation counting using a low-background liquid scintillation spectrometer-radiometer Quantulus-1220. Each of the measured samples was diluted with an organic scintillator Optiphase "HISAFE" 3 up to a volume of $20 \mathrm{ml}$ and elements spectra were obtained. (During ${ }^{10-30 ~} \mathrm{~min}$ ). The simulations of spectra ${ }^{14} \mathrm{C}$, ${ }^{90} \mathrm{Sr}$, and ${ }^{\circ} \mathrm{Y}$ were conducted, using the IAEA Library database to determine the detection conditions of $\beta^{-}$spectra of the Quantulus-1220 installed in KINR NAS of Ukraine. The results are shown in Fig. 3 and Fig. 4 (a), (b).

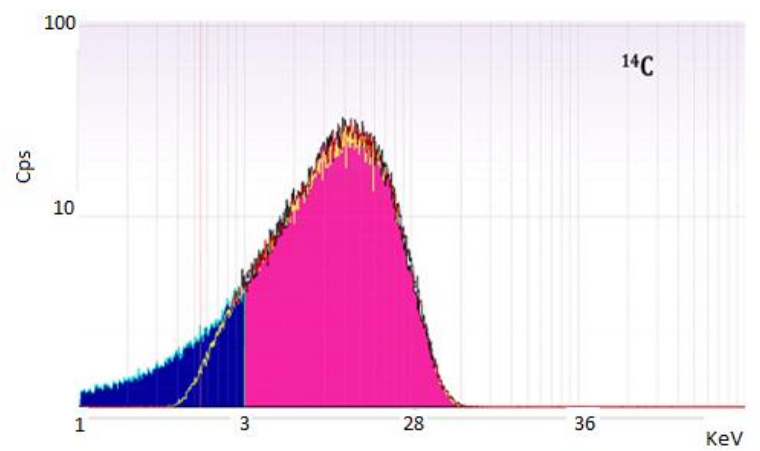

Figure 3. Simulation of the experimental ${ }^{14} \mathrm{C}$ spectrum.

The spectrum of ${ }^{14} \mathrm{C},{ }^{90} \mathrm{Sr}$ i ${ }^{\circ} \mathrm{Y}$ from the IAEA Library was simulated by the Monte-Carlo method (deposited spectrum). The efficiency of radionuclide detecting was calculated using the GEANT 4 [23].

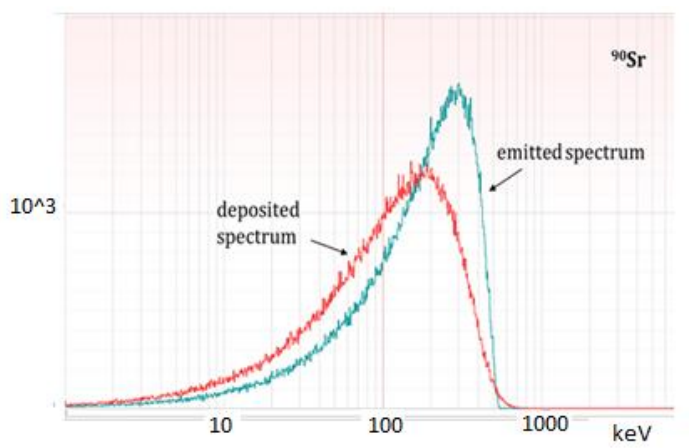

(a)

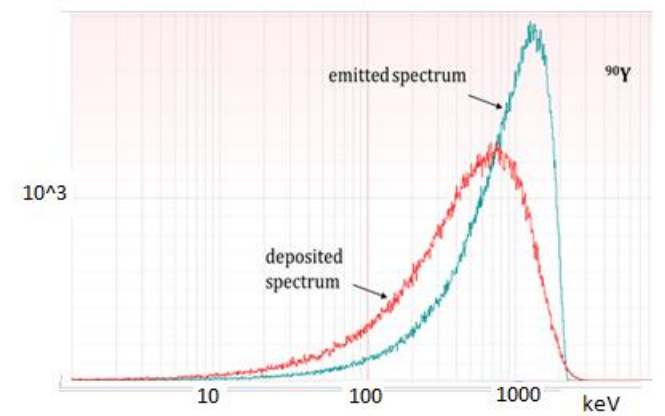

(b)

Figure 4. Comparison of the deposited spectrum and emitted spectrum: (a) for ${ }^{90} \mathrm{Sr}$; (b) for ${ }^{\circ} \mathrm{Y}$.

The low energy region (less than 8-10 keV) of the deposited model spectrum does not correspond to the experimental one (Fig. 3). However, for the other (higher) energy there is good correspondence between the processed spectrum of ${ }^{14} \mathrm{C}$ and emitted spectrum of ${ }^{14} \mathrm{C}$. According to publication [8], various physical, chemical, and optical processes in the source and detector decrease the detection efficiency of low-energy particles, i.e. shifting and quenching the obtained experimentally spectrum, as can be seen in Figures 4 (a) and (b).

As can be seen, there is a little less correspondence between emitted and deposited $\beta^{-}$-spectra for ${ }^{\circ} \mathrm{Sr}$ and ${ }^{90} \mathrm{Y}$ than for ${ }^{14} \mathrm{C}$ spectra. However, this analysis allows us to consider the errors caused by quenching and shifting of the spectrum.

\section{RESULTS AND DISCUSSION}

\subsection{Chemical separation of the stable strontium, yttrium, and zirconium ions}

Dowex HCR S/S resin showed increased selectivity for zirconium cations at an initial concentration of elements of the order of $10 \mathrm{ng} / \mathrm{ml}$. However, at higher concentrations, this adsorbent does not show selectivity for zirconium cations and adsorbs all three elements in approximately equal amounts. In general, this ion exchanger intensively absorbs yttrium cations. The Dowex 1x8 adsorbent separates strontium and zirconium due to the complete absence of adsorption of strontium cations. However, this resin together with zirconium ions adsorbs a small number of yttrium ions.

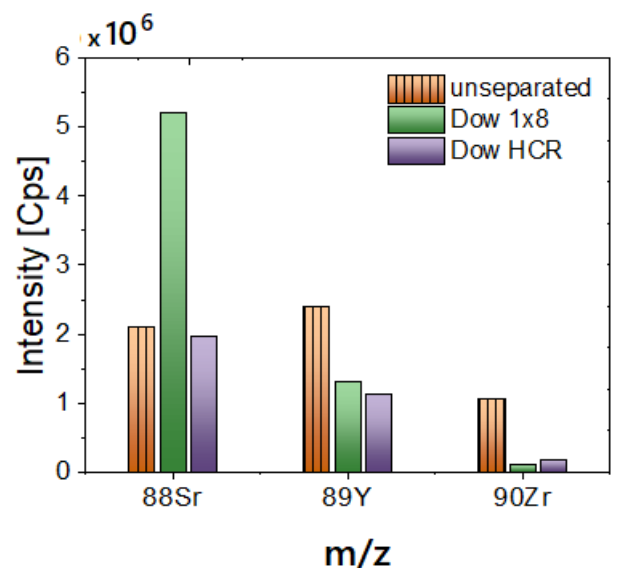

(a)

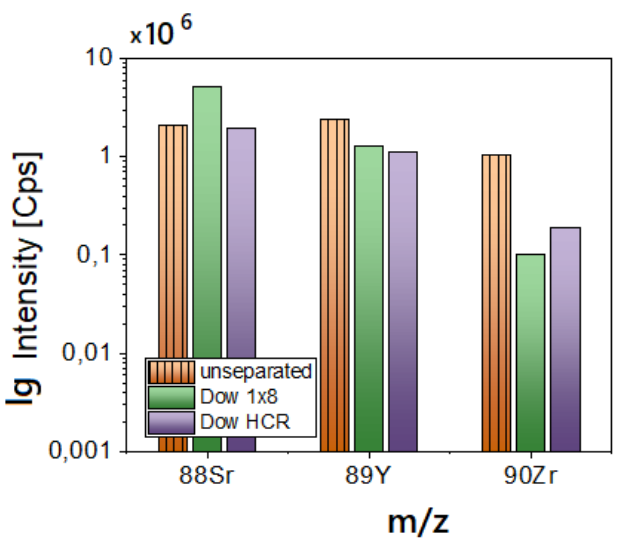

(b)

Figure 5. Results of separation by Dowex 1x8 and Dowex HCR s/s (initial concentration $10 \mathrm{ng} / \mathrm{g}$ ). 
The effective separation of strontium and zirconium ions by Dowex $1 \mathrm{x} 8$ occurs in a $5 \% \mathrm{HCl}$ medium and for subsequent analysis using ICP-MS a solution of $5 \% \mathrm{HCl}$ is evaporated for 5 hours, and then the dry residue is dissolved in $2 \% \mathrm{HNO}_{3}$ (Optima). The most effective adsorbent for the separation of strontium, yttrium, and zirconium ions was mesoporous titanium dioxide. This adsorbent selectively absorbs zirconium cations against the background of excess strontium and yttrium ions from $2 \% \mathrm{HNO}_{3}$ at initial concentrations of the studied cations $10 \mathrm{ng} / \mathrm{ml}$ and $100 \mathrm{ng} / \mathrm{ml}$.

Selective zirconium ions adsorption by $\mathrm{TiO}_{2}$ can be explained by a combination of electrostatic and steric effects. It is concluded that $\mathrm{TiO}_{2}$ with the chemically modified surface is the most optimal material for the separation of $\mathrm{Sr}^{2+}, \mathrm{Y}^{3+}, \mathrm{Zr}^{4+}$ concentrations of $10-100 \mathrm{ng} / \mathrm{ml}$ among studied adsorbents.
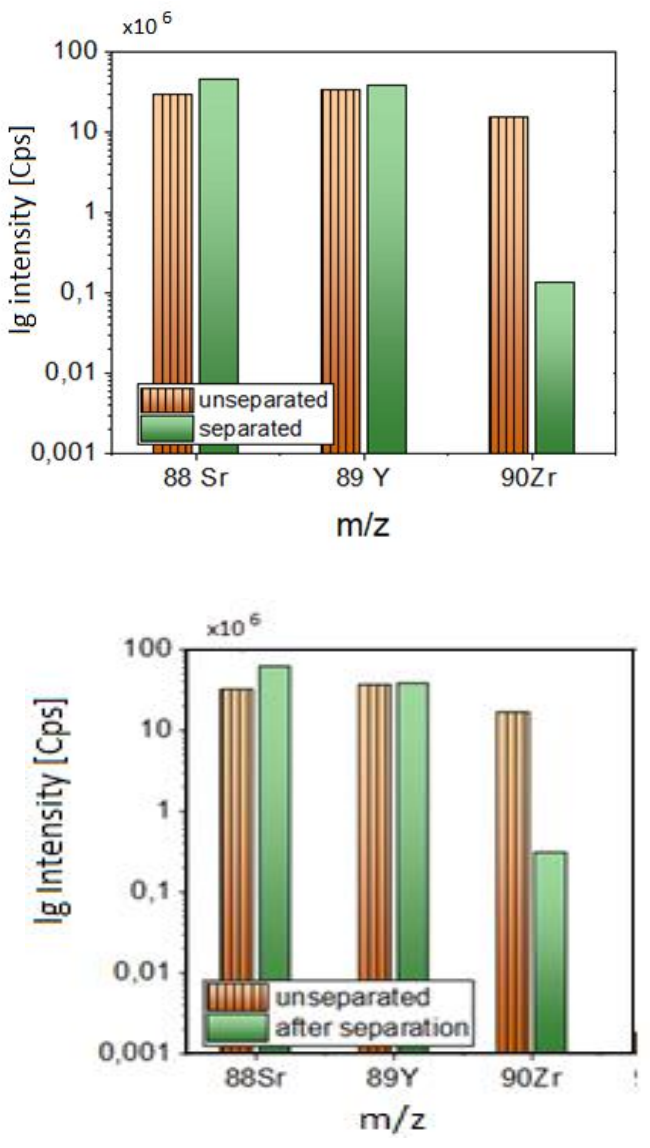

Figure 6. ICP-MS spectrum of initial mixture and mixture of the elements after chemical separation. (initial concentration $100 \mathrm{ng} / \mathrm{g}$ ): (a) solution volume is $7 \mathrm{ml}$, adsorbent mass is 70 $\mathrm{mg}$; (b) solution volume is $2 \mathrm{ml}$, adsorbent mass is $20 \mathrm{mg}$.

\subsection{Age dating of the ${ }^{90} \mathrm{Sr}$-containing compound using chemical separation of strontium and zirconium ions onto titanium dioxide}

Previous studies on the separation of strontium, yttrium, and zirconium using various adsorbents have shown that titanium dioxide is the most effective adsorbent tested in this work for these elements' separation. Therefore, for age dating of ${ }^{\circ 0} \mathrm{Sr}-9^{\circ} \mathrm{Y} \beta^{-}$source the titanium dioxide was chosen. The investigated source was fabricated in 1991, so the age of investigated source was approximately 30.2 years. It should be noted, that the "age" of any radioactive device or compound is the date of its last chemical separation [1]. The results on separation of ${ }^{\circ} \mathrm{Sr}$ and ${ }^{90} \mathrm{Zr}$ are shown in Figures 7 (a) and (b).

As can be seen, in the liquid ${ }^{\circ 0} \mathrm{Sr}-90 \mathrm{Y} \beta^{-}$- source there are a lot of stable isotopes ${ }^{88} \mathrm{Sr}$ and ${ }^{89} \mathrm{Y}$ (almost $3 \cdot 10^{-3} \mathrm{mg} / \mathrm{ml}$ ). Despite this, the adsorbent selectively reduced the peak with a mass of $90 \mathrm{amu}$. The fact that zirconium was adsorbed can be checked by reducing the peak of ${ }^{91} \mathrm{Zr}$, which was present in the source, as an admixture.

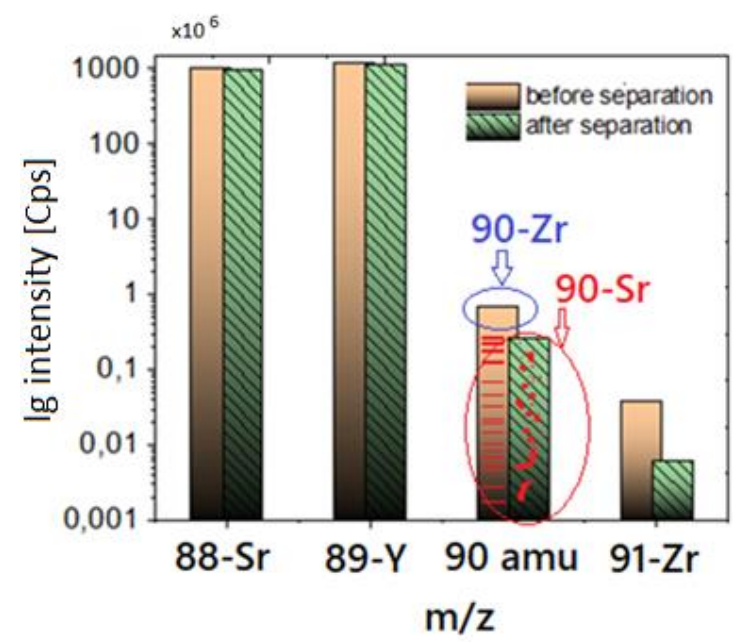

Figure 7. ICP-MS spectrum of ${ }^{\circ} \mathrm{Sr}-{ }^{\circ} \mathrm{Y} \beta^{-}$-source before and after selective adsorption of ${ }^{\circ} \mathrm{Zr}$ by the titanium dioxide.

According to Formula (1), based on Bateman equations, the age of the radioactive source can be calculated.

$$
T=\frac{1}{\lambda} \ln \left(1+\frac{N_{D}}{N_{P}}\right)
$$

In this formula $\lambda$ is ${ }^{90} \mathrm{Sr}$ decay constant; $N_{D}$ and $N_{P}-$ number of nuclei of daughter and parent nuclides, respectively.

The formation of poly ions and tailoring effects were considered during the ICP-MS analysis. The effectiveness of strontium, yttrium, or zirconium ion registration by ICP-MS was calculated using the spectra of the mixture with a concentration of $10 \mathrm{ppb}$ of each ion.

Age of ${ }^{90} \mathrm{Sr}-{ }^{\circ} \mathrm{Y} \quad \beta^{-}$-source, calculated using the chemical separation of ${ }^{\circ} \mathrm{Sr}$ and ${ }^{90} \mathrm{Zr}$ by titanium dioxide is $31.9 \pm 1$ year.

\subsection{Age dating using a combination of liquid} scintillation counting of ${ }^{\circ} \mathrm{Sr}$ and ICP-MS analysis

The $\beta^{-}$- spectrum of the ${ }^{90} \mathrm{Sr}-90 \mathrm{Y} \beta^{-}$- source was measured using the liquid scintillation spectrometerradiometer Quantulus 1220 according to the procedure described in paragraph 2.5. The effectiveness of the registration of ${ }^{\circ} \mathrm{Sr}$ was determined. The errors caused by ${ }^{\circ} \mathrm{Y}$, quenching, and shifting of the spectrum were considered. The mass of the sample was $0.4 \mathrm{~g}$ and then it was diluted 10-times, and $0.1005 \mathrm{~g}$ was chosen for measurement. The activity of the sample was $398 \pm 2 \mathrm{~Bq}$. Specific activity is $3960 \pm 20 \mathrm{~Bq} / \mathrm{g}$.

In addition, the spectrum of ${ }^{\circ} \mathrm{Sr}-9{ }^{\circ} \mathrm{Y} \beta$ - source was measured using ICP-MS (Fig. 8). The number of ${ }^{9} \mathrm{Zr}$ isotopes was calculated by the difference between the 
peak of 90 amu and the amount of ${ }^{90} \mathrm{Sr}$ determined by the LSC method.

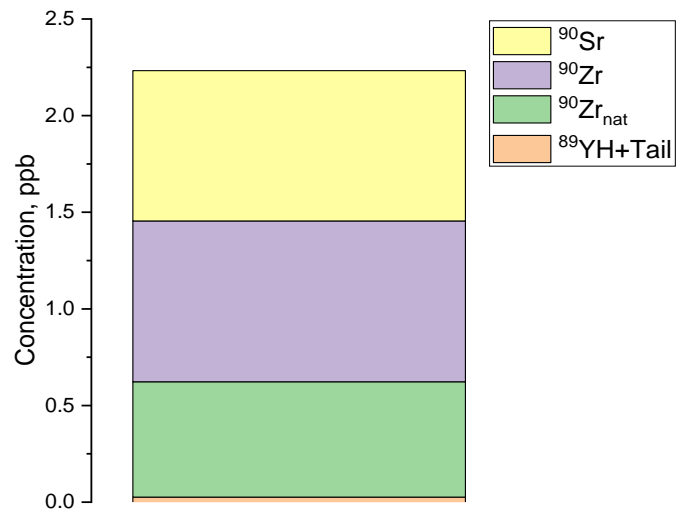

Figure 8. The concentration of ${ }^{90} \mathrm{Sr},{ }^{\circ} \mathrm{Zr}$, and ${ }^{90} \mathrm{Zr}_{\text {nat }}$ and tailoring effects in ICP-MS peak with mass $90 \mathrm{amu}$.

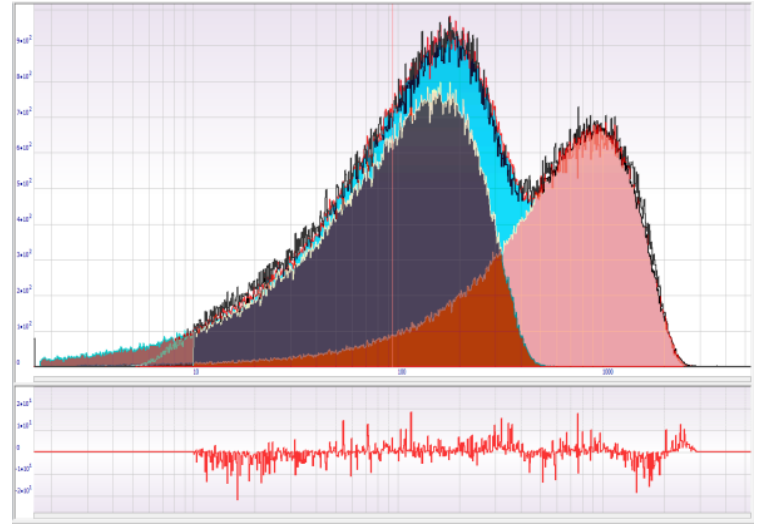

Figure 9. Liquid scintillation spectrum of ${ }^{\circ \circ} \mathrm{Sr}-9^{\circ} \mathrm{Y}$ liquid $\beta^{-}$-source.

Thus, according to the ratio of ${ }^{\circ} \mathrm{Zr} /{ }^{\circ} \mathrm{Sr}$ (calculated using the Bateman equation) the date of production of the source was calculated. Age of ${ }^{\circ 0} \mathrm{Sr}-{ }^{\circ} \mathrm{Y} \beta^{-}$-source, calculated using a combination of liquid scintillation counting of ${ }^{\circ} \mathrm{Sr}$ and ICP-MS analysis is $31.7 \pm 1.5$ years. (Real ${ }^{\circ} \mathrm{Sr}-{ }^{\circ} \mathrm{Y}$ source number: $488 / 51$ was fabricated 23.04.1991; Date of age determination 24. 06. 2021). Both methods: (a) the method with chemical separation of ${ }^{\circ} \mathrm{Zr}$ by $\mathrm{TiO}_{2}$ and further ICP-MS analysis of residual concentrations of ${ }^{\circ} \mathrm{Sr}$, and (b) combination of LSC of ${ }^{90} \mathrm{Sr}$ and ICP-MS analysis of peak with mass $90 \mathrm{amu}$ provide similar results in radio chronometry of ${ }^{\circ} \mathrm{Sr}$ contained compound, i.e. age-dating of liquid ${ }^{\circ} \mathrm{Sr}-9{ }^{\circ} \mathrm{Y}$ $\beta^{-}$- source, and could validate each other. However, the method with chemical separation (method (a)) will be preferable for the age dating of the younger ${ }^{90} \mathrm{Sr}$ radioactive source. A very large amount of ${ }^{\circ} \mathrm{Sr}$ (natural ${ }^{9} \mathrm{Zr}$ and ${ }^{89} \mathrm{Y}^{1} \mathrm{H}$ ) compared with a small amount of the radiogenic ${ }^{\circ} \mathrm{Zr}$ will increases the uncertainty, and add some limitations in the application of method (b).

\section{CONCLUSION}

The results of the present work have shown, that Dowex HCR S/S resin showed increased selectivity for zirconium cations at an initial concentration of elements of the order of $10 \mathrm{ng} / \mathrm{ml}$. However, at higher concentrations, this adsorbent does not show selectivity for zirconium cations and adsorbs all three elements in approximately equal amounts. In addition, this ion exchanger intensively absorbs yttrium cations. The Dowex 1x8 resin separates strontium and zirconium. However, this resin together with zirconium ions adsorbs significant amounts of yttrium ions.

It is concluded that $\mathrm{TiO}_{2}$ is the most optimal material for the chemical separation of $\mathrm{Sr}^{2+}, \mathrm{Y}^{3+}, \mathrm{Zr}^{4+}$ from their mixture with concentrations of $10-100 \mathrm{ng} / \mathrm{ml}$ at $\mathrm{pH}=0-1$, among studied adsorbents.

Age of ${ }^{90} \mathrm{Sr}-{ }^{\circ} \mathrm{Y} \quad \beta^{-}$-source, calculated using the method of the chemical separation of ${ }^{90} \mathrm{Sr}$ and ${ }^{90} \mathrm{Zr}$ by the titanium dioxide and further ICP-MS analysis is 31.9 \pm 1 year.

Age of ${ }^{90}{ }^{\circ}-{ }^{90} \mathrm{Y} \quad \beta^{-}$-source, calculated using a combination of liquid scintillation counting of ${ }^{\circ} \mathrm{Sr}$ and ICP-MS analysis $31.7 \pm 1.5$ years. (Real ${ }^{90} \mathrm{Sr}-{ }^{90} \mathrm{Y}$ source number: 488/51 was fabricated 23.04.1991). Both methods provide similar results in radio chronometry of ${ }^{90} \mathrm{Sr}$-contained compound, i.e. age-dating of liquid ${ }^{90} \mathrm{Sr}-{ }^{\circ} \mathrm{Y} \beta^{-}$- source, and could validate each other. However, the method with chemical separation (method (a)) will be preferable for the age dating of the younger ${ }^{\circ} \mathrm{Sr}$ radioactive source. A very large amount of ${ }^{90} \mathrm{Sr}$ (natural ${ }^{90} \mathrm{Zr}$ and ${ }^{89} \mathrm{Y}^{1} \mathrm{H}$ ) compared with a small amount of the radiogenic ${ }^{9} \mathrm{Zr}$ will increases the uncertainty, and add some limitations in the application of method (b).

Acknowledgments: This work was supported by a research grant in Nuclear Forensics. STCU [Project 9906].

\section{REFERENCES}

1. K. Mayer, M. Wallenius, T. Fanghänel, "Nuclear forensic science - from cradle to maturity," J. Alloys Compd., vol. 444 - 445, pp. 50 - 56, Oct. 2007. DOI: $10.1016 /$ j.jallcom.2007.01.164

2. V. R. van Maris et al., "The behavior of parent and daughter nuclides in aerosols released in radiological dispersion events: a study of a $\mathrm{SrTiO}_{3}$ source," J. Raman Spectrosc., vol. 48 no. 4, pp. $549-559$, Apr. 2017

DOI: $10.1002 /$ jrs.5076

3. N. Kavasi, S. K. Sahoo, H. Arae, T. Aono, Z. Palacz, "Accurate and precise determination of ${ }^{90} \mathrm{Sr}$ at femtogram level in IAEA proficiency test using Thermal Ionization Mass Spectrometry," Sci. Rep., vol. 9, no. 1, 16532, Nov. 2019.

DOI: $10.1038 / \mathrm{s} 41598-019-52890-3$ PMid: 31712653 PMCid: PMC6848187

4. S. C. Wilschefski, M. R. Baxter, "Inductively Coupled Plasma Mass Spectrometry: Introduction to Analytical Aspects," Clin. Biochem. Rev., vol. 40, no. 3, pp. 115 - 133, Aug. 2019.

DOI: $10.33176 / A A C B-19-00024$

PMid: 31530963

PMCid: PMC6719745

5. W. R. Hendee, E. R. Ritenour, Medical Imaging Physics, 4th ed., New York (NY), USA: J. Wiley and Sons, 2002, p. 353.

DOI: $10.1002 / 0471221155$

6. D. Mc Alister, "Options for Separation and Measurement of $89 \mathrm{Sr} / 90 \mathrm{Sr}$," presented at the $63^{\text {rd }}$ Conf. Radiobioassay and Radiochemical 
Measurements (RRMC), Portland (ME), USA, May 2018.

7. Principles and Applications of Liquid Scintillation Counting, National Diagnostics, Atlanta (GA), USA, 2004.

Retrieved from:

https://ehs.psu.edu/sites/ehs/files/lsc theory of operation part 1.pdf

Retrieved on: Jan. 10, 2021

8. P. Gaca, D. Reading, P. Warwick, "Application of multiple quench parameters for confirmation of radionuclide identity in radioanalytical quality control," J. Radioanal. Nucl. Chem., vol. 322, no. 3, pp. 1383 - 1390, Dec. 2019.

DOI: $10.1007 / \mathrm{s} 10967-019-06788-\mathrm{z}$

9. H. Vasylyeva et al., "Adsorption of zirconium ions by X-type zeolite," Biointerface Res. Appl. Chem., vol. 11, no. 5, pp. 13421 - 13431, Feb. 2021. DOI: 10.33263 /BRIAC115.1342113431

10. H. V. Vasylyeva et al., "Radiochemical studies of state of lanthanum micro amounts in water solution," J. Mol. Liq., vol. 118, no. 1 - 3 pp. $41-44$, Apr. 2005. https://www.doi.org.10.1016/j.molliq.2004.07.008

11. S. Yang et al., "Crystal shape engineering of anatase $\mathrm{TiO}_{2}$ and its biomedical applications," CrystEngComm, vol. 17, no. 35, pp. 6617 - 6631, Sep. 2015. https://www.doi.org.10.1039/C5CE00804B

12. I.F. Mironyuk, I. M. Mykytyn, O. Ye. Kaglyan, D. I. Gudkov, H. V. Vasylyeva, "90-Sr Adsorption from the Aquatic Environment of Chornobyl Exclusion Zone by Chemically Enhanced $\mathrm{TiO}_{2}$," Nucl. Phys. At. Energy, vol. 21, no. 4, p. 347, 2020. DOI: 10.15407/jnpae2020.04.347

13. H. Vasylyeva, I. Mironyuk, I. Mykytyn, K. Savka, "Equilibrium studies of yttrium adsorption from aqueous solutions by titanium dioxide," Appl. Radiat. Isot., vol. 168, 109473, Feb. 2021.

DOI: $10.1016 / \mathrm{j}$.apradiso.2020.109473 PMid: 33658128

14. H. Vasylyeva, I. Mironyuk, I. Mykytyn, "Adsorption of $\mathrm{Co}^{2+}$ and radioactive ${ }^{60} \mathrm{Co}$ by mesoporous $\mathrm{TiO}_{2}$," Chem. Phys. Technol. Surf., vol. 10, no. 4, pp. 446 - 457, Dec. 2019. DOI: $10.15407 / \mathrm{hftp10.04.446}$

15. I. Mironyuk, I. Mykytyn, H. Vasylyeva, K. Savka, "Sodium-modified mesoporous $\mathrm{TiO}_{2}$ : Sol-gel synthesis, characterization and adsorption activity toward heavy metal cations," J. Mol. Liq., vol. 316, 113840 , Oct. 2020.

DOI: 10.1016/j.molliq.2020.113840

16. H. Vasylyeva, I. Mironyuk, I. Mykytyn, N. Danyliuk, "Adsorption of Barium and Zinc Ions by Mesoporous $\mathrm{TiO}_{2}$ with Chemosorbed Carbonate Groups," Phys. Chem. Solid State, vol. 20, no. 3, p. 282, Oct. 2019. DOI: $10.15330 /$ pcss.20.3.282-290

17. H. Vasylyeva et al., "Application of Titanium Dioxide for Zirconium Ions Adsorption and Separation from a Multicomponent Mixture," Phys. Chem. Solid State, vol. 22, no. 3, pp. 460 - 469, Aug. 2021. DOI: $10.15330 /$ pcss.22.3.460-469

18. M. M. S. Ali, E. A. Abdel-Galil, M. M. Hamed, "Removal of strontium radionuclides from liquid scintillation waste and environmental water samples," Appl. Radiat. Isot., vol. 166, 109357, Dec. 2020.

DOI: $10.1016 /$ j.apradiso.2020.109357

PMid: 32755756

19. A. Surrao et al., "Improving the separation of strontium and barium with Sr Resin using chelating eluent solutions," J. Radioanal. Nucl. Chem., vol. 319, no. 3, pp. 1185 - 1192, Mar. 2019. DOI: 10.1007/s10967-019-06432-w

20. K. Kołacińska, Z. Samczyński, J. Dudek, A. Bojanowska-Czajka, M. Trojanowicz, "A comparison study on the use of Dowex 1 and TEVA-resin in determination of ${ }_{99} \mathrm{Tc}$ in environmental and nuclear coolant samples in a SIA system with ICP-MS detection," Talanta, vol. 184, pp. $527-536$, Jul. 2018.

DOI: $10.1016 /$ j.talanta.2018.03.034 PMid: 29674079

21. E. P. Horwitz, D. R. McAlister, A. H. Thakkar, "Synergistic enhancement of the extraction of trivalent lanthanides and actinides by tetra-(n-octyl) diglycolamide from chloride media," Solvent Extr. Ion Exch., vol. 26, no. 1, pp. 12 - 24, 2008. DOI: $10.1080 / 07366290701779423$

22. K. M. Mackay, R. A. Mackay, W. Henderson, Introduction to modern inorganic chemistry, $5^{\text {th }}$ ed., London, UK: Blackie Academic \& Professional an imprint of Chapman and Hall, 1996.

23. S. Agostinelli et al., "Geant4 - a simulation toolkit," Nucl. Instrum. Methods Phys. Res. A vol. 506, no. 3, pp. $250-303$, Jul. 2003.

DOI: 10.1016/So168-9002(03)01368-8 